\title{
https://doi.org/10.30853/filnauki.2020.6.24
}

\section{Королков Анна}

Взаимосвязь эмоций, иронии и экстремальных событий (на материале комментариев об инциденте в Керченском проливе)

Данная статья рассматривает иронию как приём речевых актов эмоционального воздействия в современных публицистических текстах. Цель исследования - выявить место и функцию данного лингвистического приёма в семантической структуре аналитических комментариев об экстремальном событии. Научная новизна исследования заключается в разработке основных характеристик авторского приёма, используемого с целью вызвать у читателей определённые эмоции и оставить след в их восприятии происшедшего экстремального события, вызвавшего в обществе безусловно большой резонанс. Полученные результаты показали, что существует прямая взаимосвязь использования приема иронии с главным намерением автора аналитических текстов - вызвать эмоциональную реакцию у адресата.

Адрес статьи: www.gramota.net/materials/2/2020/6/24.html

\section{Источник}

Филологические науки. Вопросы теории и практики

Тамбов: Грамота, 2020. Том 13. Выпуск 6. С. 144-148. ISSN 1997-2911.

Адрес журнала: www.gramota.net/editions/2.html

Содержание данного номера журнала: www.gramota.net/materials/2/2020/6/

\section{() Издательство "Грамота"}

Информация о возможности публикации статей в журнале размещена на Интернет сайте издательства: www.gramota.net Вопросы, связанные с публикациями научных материалов, редакция просит направлять на адрес: phil@gramota.net 
Данная статья рассматривает иронию как приём речевых актов эмоционального воздействия в современных публицистических текстах. Цель исследования - выявить место и функцию данного лингвистического приёма в семантической структуре аналитических комментариев об экстремальном событии. Научная новизна исследования заключается в разработке основных характеристик авторского приёма, используемого с иелью вызвать у читателей определённые эмоции и оставить след в их восприятии происшедшего экстремального события, вызвавшего в обществе безусловно большой резонанс. Полученные результаты показали, что существует прямая взаимосвязь использования приема иронии с главным намерением автора аналитических текстов - вызвать эмочиональную реакцию у адресата.

Ключевые слова и фразы:: ирония; речевой акт; эмоциональное воздействие; экстремальное событие; аналитический комментарий.

\section{Королков Анна}

Санкт-Петербургский государственный университет anna.simekova12@gmail.com

\section{Взаимосвязь эмоций, иронии и экстремальных событий (на материале комментариев об инциденте в Керченском проливе)}

В настоящее время мы всё чаще сталкиваемся с ироническими высказываниями в текстах, которые освещают экстремальные события. В нашем исследовании мы сделали акцент на взаимосвязи освещения таких экстремальных событий и семантической структуры иронических аналитических комментариев, в чем заключается новизна данного научного исследования.

Главными признаками экстремального события являются: 1) участие человека; 2) неожиданность, быстротечность; 3) угроза жизни человека или группы людей; 4) большой резонанс в обществе. Первый признак, несомненно, важен, уже Н. Д. Арутюнова приписывала ему огромное значение: «Физическое пространство может быть только местом, где разворачиваются события, происходящие в жизни людей, стран, коллективов, всего того, что живет или осмысляется как живущее... События не только происходят в жизни людей, но в них должны принимать участие люди. События личностны и социальны» [1, с. 171]. Природные явления, которые рассматриваются с объективной точки зрения и в которых не участвует человек, мы можем назвать фактами или феноменами [12]. Второй признак экстремальных событий - неожиданность и быстротечность - делает такие события неординарными, поскольку к ним нельзя подготовиться, мы их не ожидаем и не предвидим. Третий признак не требует глубокого объяснения, такие события, как пожары в торговых центрах, стрельба в учебном заведении, международный конфликт, появление коронавируса и т.П., естественно опасны для их участников. Последний признак, по нашему мнению, несомненно, важен, так как в мире происходит ежедневно много событий, но не все вызывают в обществе такой резонанс и не все «интересны» для современной журналистики.

Для нашего исследования представляется интересным применение иронии - приёма в высказываниях, оказывающих эмоциональное воздействие на адресата. Наше внимание направлено на выявление места иронии в семантической структуре аналитических текстов, таких как аналитические комментарии. В данной статье мы представим материалы комментариев, освещающих инцидент в Керченском проливе. Это экстремальное событие произошло 25 ноября 2018 года, и его участниками были Россия и Украина. Необходимо напомнить, что данный вооруженный конфликт произошел в Керченском проливе, когда корабли Украины попытались пройти из Одессы в Мариуполь. Конфликт закончился только через год - Россия и Украина договорились об обмене 24 задержанных украинских моряков. Данное событие было освещено во многих российских изданиях, таких как «Известия», «Аргументы и факты», «Коммерсантъ», «Деловой Петербург», «Ведомости», но также вызвало интерес мировых СМИ - “The Telegraph”, “Forbes”, “BBC”, “Guardian” и т.д. Этому событию даже посвящена статья в Википедии [6]. Всё вышесказанное обосновывает актуальность данной темы.

Для выбора материала мы ограничились двумя интернет-версиями изданий - «Известия» и «АиФ». В этих периодических изданиях мы столкнулись с текстами, выходящими за рамки аналитического комментария, который по своей жанровой природе должен быть объективным, без использования эмотивных высказываний. Фактически же эти тексты являются субъективными рассуждениями автора, и авторы таких текстов зачастую «играют на эмоциях» аудитории.

Прежде чем раскрыть цель данного исследования и его результаты, представляется важным показать его теоретическую базу. В Толковом словаре С. И. Ожегова ирония толкуется как «тонкая, скрытая насмешка» [9, с. 612]. Некоторые лингвисты отмечают, что ирония выражается с помощью включения торжественной, поэтической лексики в высказывания о будничном, обыденном, низком; столкновением высокой и низкой лексики $[4$, с. $111 ; 8$, с. 25,18$]$. Как упомянуто выше, в аналитических комментариях важным типом текста является рассуждение. Именно аффектное рассуждение отличается от рационального использованием иронии, насмешки, метафоры и сравнения [11, с. 92]. И. В. Труфанова выделяет иронию как вид частного речевого акта внутри речевого акта эмоционального воздействия. Такие речевые акты по иллокутивной цели она разделяет на 7 основных групп, среди них также речевые акты, производимые для улучшения или ухудшения эмоционального состояния слушающего, к этой группе автор относит и иронию [14, с. 311-312]. 
В лингвистике иронию часто связывают с насмешкой и с юмором. О том, который из этих двух признаков более характерен для иронии и в чем её принципиальное отличие от шутки, писала О. П. Ермакова: «Главная цель иронии в отличие от шутки - не вызвать смех, а вызвать отношение к объекту иронии» [5, с. 22]. Эта главная цель иронии проявляется, прежде всего, в публицистике, на что мы также обратили внимание в представленном исследовании. Практическая значимость данного исследования заключается в применении его результатов в области психолингвистики и анализа текста, так как речевые акты эмоционального воздействия в аналитических текстах об экстремальных событиях изучаются впервые.

Необходимо сказать, что мы относим иронию к определенному типу приема, основанного на использовании речевых актов, в нашем случае речевых актов, выражающих эмоции говорящего, с целью воздействовать на внутренний мир слушающего. Данный приём выступает в роли предмета нашего исследования, причём объектом являются частные речевые акты эмоционального воздействия, в которых проявляется ирония. Поставленная цель исследования предполагает решение следующих задач: отобрать единицы данного исследования из выбранных текстов, освещающих экстремальные события; на основании отбора составить анкету для проведения эксперимента; проанализировать полученные результаты и сравнить их с выходными единицами, показать возможность разграничения разных типов речевых актов, в которых проявляется ирония, чтобы выявить основную функцию данного лингвистического приёма. Для решения поставленных задач нами были использованы следующие методы исследования: описательно-аналитический, сопоставительный и экспериментальный.

Прежде чем было проведено анкетирование, мы проанализировали два текста и в них выделили 12 самых ярких фрагментов, представляющих собой высказывания авторов на тему экстремального события. По мнению многих учёных, классифицирующих речевые акты по их основным функциям, таких как И. Н. Борисова, Л. А. Пиотровская, И. В. Труфанова [3; 10; 14], эмотивные речевые акты преследуют следующие цели: а) выразить свои эмоции; б) дать оценку событию или его участникам; в) выразить у читателей эмоциональную реакцию. Согласно нашим наблюдениям, в некоторых высказываниях автор преследует одну из трёх целей в большей степени, чем оставшиеся две. Так, например, в следующем отрывке преобладает выражение эмоции злости. Рассмотрим отрывок подробнее:

«За какие грехи Украине такое наказание? Почему жизни украинских моряков вверень человеку, которому, по совести, нельзя доверять и мусорное ведро? Ответа нет. Украинский циик зльх клоунов продолжсает свою работу» [13]. Индикаторами данного речевого акта являются: инвектива «человеку, которому, по совести, нельзя доверять и мусорное ведро», риторический вопрос (в начале) и метонимия «циик зльх клоунов». Важно пояснить, что автор в данном высказывании выражает эмоцию злости, чем также безусловно влияет на переживание читателя. Итак, мы не считаем необходимым разграничивать эмотивные речевые акты и речевые акты эмоционального воздействия, поскольку проявление своих эмоций вслух с помощью языка всегда подразумевает воздействие на нашего собеседника. Язык по своей сути всегда направлен на адресата, говорящий подразумевает собеседника, а в публицистике тем более. Издания напрямую зависят от читателей, от того, какова их реакция, что проявляется чаще всего в аналитических публицистических текстах, которые рассуждают о значимом для общества событии. В текстах, освещающих неординарные события, по-нашему экстремальные, большую роль играет чувство страха. Авторы этих текстов также в них вкладывают свои эмоции, при помощи которых пытаются вызвать определённую эмоциональную реакцию у читателей. Данное явление мы поясним дальше в анализе результатов анкетирования.

\section{Анкетирование}

Данное анкетирование было проведено среди 15 испытуемых в возрасте 21-35 лет: 8 женщин и 7 мужчин. Пять анкет присутствующие заполнили на нашем выступлении с докладом на Международной конференции молодых филологов в Таллине в 2020 г. [7, с. 60-61], где мы частично представили результаты нашего анализа фрагментов выбранных текстов, чтобы не повлиять на ответы участников. Все испытуемые - носители русского языка, что сразу обеспечивает полное понимание текста, а также способность различить иронию. Участие приняли испытуемые разных специальностей - программист, филолог, преподаватели русского языка как иностранного, русского языка и литературы, иностранных языков, специалисты техподдержки. Структура анкеты состоит из трёх основных частей - вопросов, причём в первом вопросе представлено всего 12 фрагментов текстов из издания «Известия» [2] и «АиФ» [13].

В анкетировании были поставлены данные вопросы:

1. В каком из представленных частных речевых актов присутствует ирония?

2. Какую эмоцию авторы аналитических комментариев вызвали у читателей?

3. Какова была цель автора, использовавшего данные речевые акты?

В первом блоке, как мы упомянули выше, было представлено 12 высказываний, которые, согласно нашему анализу, использованы с целью оказать эмоциональное воздействие на читателя. В задании испытуемые должны были выбрать те, в которых, по их мнению, присутствует ирония.

Двенадцать испытуемых обозначили следующее высказывания:

Украинский ичирк злых клоунов дает представления ежедневно. Не успели украинские граждане переварить алкошоу от главы государства, как на манеж вышел новый артист [Там же].

На втором месте, согласно результатам анкетирования, следующее высказывание (10): $3 a$ какие грехи Украине такое наказание? Почему жизни украинских моряков вверены человеку, которому, по совести, нельзя доверять и мусорное ведро? Ответа нет. Украинский циик зльх клоунов продолжает свою работу [Там же].

Наконец, приводим высказывание, которое только двое посчитали ироничным: Стараниями украинских медиа это незначительное событие было раздуто до вселенских масштабов [2]. 
Наш интерес вызвал выбор второго высказывания, которое обозначили 10 участников анкетирования из 15. Мы полагаем, что второе высказывание за счёт использования риторических вопросов напоминает внутреннюю речь автора, в которой проявляются его злость и гнев. Переход внутренней речи автора, в которой он на свои же вопросы отвечает, во внешнюю речь делает данное эмотивное высказывание высказыванием эмоционального воздействия, о чём также в своё время писала И. В. Труфанова [14, с. 21]. Данное наблюдение доказывает, что между типами речевых актов, выражающих свои эмоции, речевых актов, эмоционально оценивающих внешний мир, и теми, которые направлены на конкретного адресата, очень тонкая грань, которая нуждается в дальнейшем исследовании.

Последнее высказывание в нашем анализе текстов мы не посчитали ироничным, так как в нём использованная антитеза незначительное - вселенских масштабов не даёт оценку конкретному человеку - объекту, а только общей группе людей (медиа). Для читателя этот образ представляется размытым и неопределённым, что и нарушает главное условие успешного иронического приёма. В этом высказывании также хотим обратить внимание на источник - газету «Известия», которую по стилю можно отнести к качественной прессе, где мнения - комментарии составлены публичными лицами, специалистами по данной теме, в отличие от комментариев таблоидной прессы (АиФ).

Во втором задании испытуемые должны были выбрать тот тип эмоций, который они испытывали после ознакомления с 12 высказываниями по отношению к участникам экстремального события (далее - ЭС) (см. Таблицу 1).

Таблица 1

\begin{tabular}{|l|c|c|c|c|c|}
\hline & \multicolumn{5}{|c|}{ Эмоция, которую респонденты испытывают } \\
\hline \multicolumn{1}{|c|}{ Участники ЭС } & гнев & страх коношению участникам экстремального события (ЭС) \\
\hline Россия & 2 & 0 & сомнение & удивление & интерес \\
\hline Украина & 1 & 3 & 4 & 2 & 3 \\
\hline
\end{tabular}

Мы видим, что больше всего участники анкетирования почувствовали сомнение по отношению к Украине (6), причём никто из них не испытывал страх по отношению к России. Для нашего исследования интересно прийти к выводу, что сомнение испытуемые почувствовали не только по отношению к Украине, как это по нашему анализу предполагалось, но и к России (4). В ранее проведенных исследованиях мы также предполагали, что, используя иронию как приём в речевых актах эмоционального воздействия, автор намеренно выражает свои эмоции - злость и гнев, которые у читателей превращаются в эмоцию сомнения. Так как ирония направлена, как было упомянуто выше, на конкретного человека, в нашем случае - участника экстремального события, сомнение направлено, согласно результатам нашего исследования, на Украину и на втором месте, с разницей в два голоса - на Россию.

Итак, переходим к заключительному, третьему, блоку анкетирования. В нём испытуемые должны были обозначить, с какой целью автор использовал данное высказывание. Данный блок членится на 4 меньших блока, в первом участники могли выбрать из трёх целей, о них мы писали выше (см. введение). Так как мы полагаем, что данное высказывание: «За какие грехи Украине такое наказание? Почему жизни украинских моряков вверены человеку, которому, по совести, нельзя доверять и мусорное ведро? Ответа нет. Украинский цирк зльхх клоунов продолжает свою работу» [13] автор использовал с целью выразить свои эмоции, которые переданы при помощи таких лингвистических средств и приёмов, как инвектива и риторический вопрос, но сразу после попадания их в текст, опубликованный и адресованный для конкретного адресата, этот эмотивный речевой акт приобретает воздействующую функцию и становится речевым актом эмоционального воздействия. Если его классифицировать как частный речевой акт эмоционального воздействия, можно полагать, что речь идёт об унижении/оскорблении. Глагол унизить в Словаре С. И. Ожегова толкуется следующим образом: «оскорбить чье-н. достоинство, самолюбие. У. насмешкой» [9, с. 2095]. Как можно заметить, унижение напрямую связано с насмешкой, являющейся основной характеристикой иронии. Далее мы рассмотрим ответы респондентов, которые мы для наглядности представим ниже в виде диаграммы (см. Диаграмму 1).

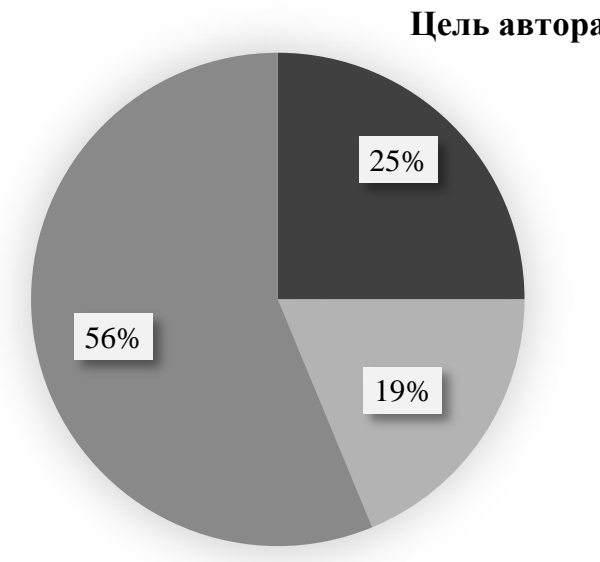

в выразить свои эмоции

дать оценку

вызвать эмоц. реакцию

Диаграмма 1. Ответы респондентов на вопрос 3.1 
На круговой диаграмме изображены три варианта ответа на вопрос: «С какой целью, по вашему мнению, автор использовал данное высказывание?». Как мы видим, 56\% испытуемых ответили, что главная цель, преследуемая автором, - вызвать эмоциональную реакцию у читателя. На втором месте ответ выразить свои эмоции - его обозначили $25 \%$ респондентов. Причём только на 4\% меньше ответили, что автор хотел дать оценку событию или его участнику. Больше половины респондентов считают, что вышеприведенное высказывание можно отнести к группе речевых актов эмоционального воздействия, что подтверждает предложенную нами гипотезу.

Во втором, третьем и четвёртом вопросах третьего блока мы преследовали несколько другую цель: мы попросили респондентов выбрать один из трёх частных речевых актов - критика, насмешка, оскорбление, так как именно эти три частных речевых акта эмоционального воздействия были выделены нами в предварительном анализе текстов. Второе высказывание «В биографии 54-летнего Игоря Воронченко прекрасно всё. Он появился на свет в поселке Бабаи, и вдохновленный советским патриотическим кино решил стать военнылм» [13] по результатам нашего анализа можно определить как насмешку автора по отношению к украинскому адмиралу. Согласно результатам анкетирования, 87\% испытуемых данное высказывание принимают за насмешку, только 13\% - как критику, и никто из них не посчитал, что оно является оскорблением (см. Диаграмму 2).

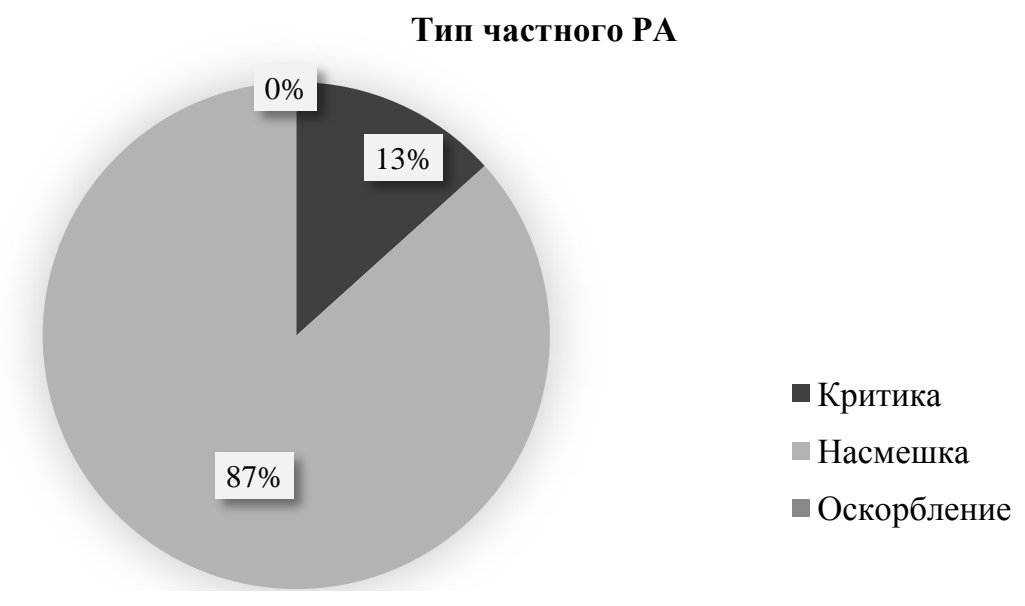

Диаграмма 2. Ответы респондентов на вопрос 3.2

Третье высказывание «Украинский изик злых клоунов дает представления ежедневно. Не успели украинские граждане переварить алкошоу от главы государства, как на манеж вылел новый артист» [Там же] мы принимаем за оскорбление, такого же мнения 60\% испытуемых, причём 40\% думают, что данное высказывание является насмешкой, и никто из них не принимает его за критику (см. Диаграмму 3 ).

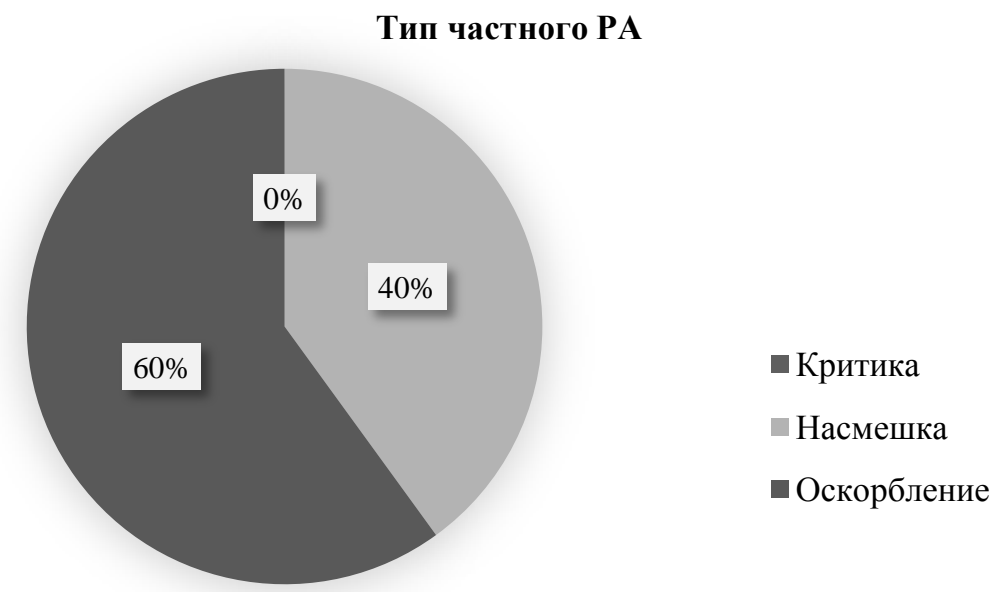

Диаграмма 3. Ответы респондентов на вопрос 3.3

Наконец, представим четвёртое высказывание из третьего блока анкеты: «Шумиха в прессе, очевидно, подняла самомнение украинских моряков. И вот 25 ноября они попытались провокацию повторить» [2]. Данное высказывание, по нашему мнению, можно определить как насмешку, что также подтверждают результаты анкетирования (53\%). Интересно, что разница в ответах насмешка и критика небольшая - 19\%, и $13 \%$ испытуемых определили его как оскорбление. В данном речевом акте важную роль сыграло вводное слово очевидно, которое подчеркивает иронический тон автора, что, собственно говоря, и определяет его как насмешку (см. Диаграмму 4). 


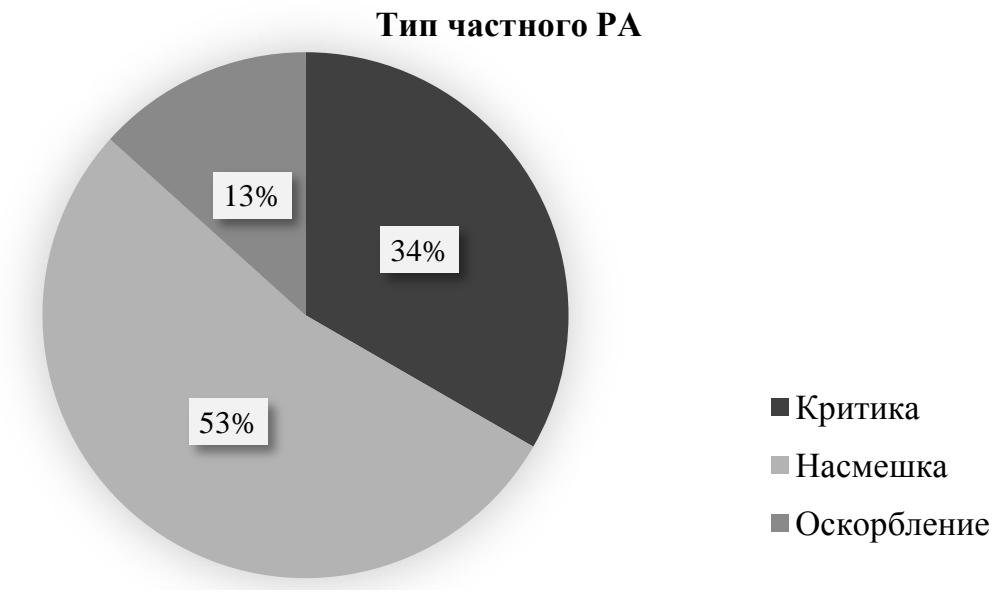

Диаграмма 4. Ответы респондентов на вопрос 3.4

Согласно поставленной цели и задачам мы пришли к следующим выводам.

В семантической структуре аналитических текстов, освещающих экстремальное событие, ирония представляет собой приём речевых актов эмоционального воздействия. Функция иронии в аналитических комментариях заключается в роли посредника между эмоциями автора и эмоциями читателя, т.е. она трансформирует эмоции автора, как показали результаты исследования. В приведённых текстах эмоции автора злость и гнев - трансформируются в эмоции адресата - сомнение, что также подтверждают результаты анкетирования. Согласно результатам исследования, главная цель автора - вызвать эмоциональную реакцию у читателя, что также доказывает, что использованные автором высказывания являются речевыми актами эмоционального воздействия. Ирония чаще всего является составляющей таких речевых актов эмоционального воздействия, как насмешка и оскорбление.

\title{
Список источников
}

1. Арутюнова Н. Д. Типы языковых значений: оценка, событие, факт. М.: Наука, 1988. 339 с

2. Болтенков Д. Берег сберёг // Известия. 2018. 27 ноября.

3. Борисова И. Н. Русский разговорный диалог: структура и динамика. М.: ЛИБРОКОМ, 2009. 320 с.

4. Девкин В. Д. Диалог. Немецкая разговорная речь в сопоставлении с русской. М.: Высшая школа, 1981.160 с.

5. Ермакова О. П. Ирония и ее роль в жизни языка. Калуга: Изд-во КГПУ им. К. Э. Циолковского, 2005. 204 с.

6. Инцидент в Керченском проливе [Электронный ресурc]. URL: https://ru.wikipedia.org/wiki/Инцидент_в_Керченском_ проливе (дата обращения: 18.03.2020).

7. Королков А. Ирония как приём речевых актов эмоционального воздействия (на материале аналитических комментариев об экстремальных событиях) // Сборник тезисов участников XXI Международной конференции молодых филологов. Таллин, 2020. С. 60-61.

8. Краснянский В. В. Стилистика художественной речи (повествовательная речь): учебное пособие по спецкурсу. М.: МГУ, 1972. $36 \mathrm{c}$.

9. Ожегов С. И. Толковый словарь русского языка / под ред. проф. Л. И. Скворцова. Изд-е 28-е, перераб. М.: Мир и образование, 2014. $1376 \mathrm{c.}$

10. Пиотровская Л. А. Эмотивные высказывания как объект лингвистического исследования (на материале русского и чешского языков). СПб.: СПбГУ, 1994. $147 \mathrm{c.}$

11. Рибо Т. Логика чувств. СПб.: Изд-во О. Н. Поповой, 1906. 148 с.

12. Романова Г. С. Конструкции с общим значением событийности (на материале испанского, итальянского и французского языков): автореф. дисс. ... к. филол. н. М., 1979. 24 с.

13. Сидорчик А. Цирк адмирала Воронченко. Главком ВМСУ предложил себя Президенту РФ // Аргументы и факты. 2018. 6 декабря.

14. Труфанова И. В. Прагматика несобственно-прямой речи: дисс. ... д. филол. н. Н. Новгород, 2001. 706 с.

\section{Correlation between Emotions, Irony and Extreme Events (by the Material of Comments on the Kerch Strait Incident)}

\author{
Korolkov Anna \\ Saint Petersburg University \\ anna.simekova12@gmail.com
}

\begin{abstract}
The article considers irony as a speech act device of emotional influence in modern publicistic texts. The work aims to determine the place and function of this linguistic phenomenon in the semantic structure of analytical comments on extreme events. The study is novel in that it formulates the principal features of the author's device used with the purpose of eliciting particular emotions from the readers and leaving an imprint on their perception of extreme events, which have undoubtedly drawn close public attention. The attained results have shown that there is direct correlation between the use of the irony device and the main intention that the author of analytical texts has - to evoke an emotional response from the addressee.
\end{abstract}

Key words and phrases: irony; speech act; emotional influence; extreme event; analytical comments. 